\title{
Colonic Electromechanical Abnormalities Underlying Post-operative Ileus: A Systematic and Critical Review
}

\author{
Cameron I Wells, ${ }^{1}$ Gregory O'Grady, ${ }^{1,2,3}$ and lan P Bissett ${ }^{1,2 *}$ \\ ${ }^{1}$ Department of Surgery, Faculty of Medical and Health Sciences, The University of Auckland, New Zealand; ${ }^{2}$ Department of Surgery, \\ Auckland District Health Board, Auckland, New Zealand; and ${ }^{3}$ Auckland Bioengineering Institute, The University of Auckland, New Zealand
}

Post-operative ileus (POI) is an inevitable consequence of major abdominal surgery, and may be prolonged in up to $30 \%$ of patients. lleus is commonly presumed to result from paralysis of the GI tract, though there is little direct evidence to support this view. The aim of this review is to systematically search and critically review the literature investigating post-operative colonic electrical and mechanical activity. MEDLINE and Embase databases were systematically searched for articles investigating post-operative colonic motor or electrical activity in human patients. Nineteen original articles investigating post-operative colonic motor or electrical activity were identified. Most studies have used low-resolution techniques, with intermittent recordings of colonic motility. Numerous studies have shown that colonic electrical and motor activity does not cease routinely following surgery, but is of abnormal character for 3-6 days following laparotomy. One recent high-resolution manometry study identified hyperactive cyclic motor patterns occurring in the distal colon on the first post-operative day. Low-resolution studies have shown colonic slow waves are not inhibited by surgery, and are present even in the immediate post-operative period. Recovery of normal motility appears to occur in a proximal to distal direction and is temporally correlated with the clinical return of bowel function. No studies have investigated motility specifically in prolonged POI. Future studies should use high-resolution techniques to accurately characterise abnormalities in electrical and mechanical function underlying $\mathrm{POI}$, and correlate these changes with clinical recovery of bowel function.

(J Neurogastroenterol Motil 2019;25:36-47)

Key Words

Colon; Gastrointestinal motility; lleus; Manometry; Postoperative complications

\section{Introduction}

Following major abdominal surgery, a period of impaired gastrointestinal (GI) transit occurs, termed post-operative ileus (POI). Prolonged post-operative ileus (PPOI) has been defined as failure of GI recovery by the fourth post-operative day, as opposed to the self-limiting period of "obligatory POI" routinely occurring for
2-3 days after major abdominal surgery. ${ }^{1}$ PPOI occurs in $10-30 \%$ of patients undergoing major colorectal surgery, depending on the type of operation and presence of risk factors. Ileus is associated with patient discomfort, prolonged hospital stays, and other postoperative complications, resulting in an estimated economic impact of US $\$ 1.5$ billion annually in the United States alone. ${ }^{2}$

Despite the common occurrence of POI and its impact on patients and healthcare systems, the precise aberrations in motil-

Received: January 23, 2018 Revised: June 20, 2018 Accepted: July 21, 2018

() This is an Open Access article distributed under the terms of the Creative Commons Attribution Non-Commercial License (http://creativecommons. org/licenses/by-nc/4.0) which permits unrestricted non-commercial use, distribution, and reproduction in any medium, provided the original work is properly cited.

*Correspondence: Ian P Bissett, MBChB, MD, FRACS

Department of Surgery, University of Auckland, Private Bag 92019, Auckland Mail Center 1142, New Zealand Tel: +64-9-3737599, Fax: +64-9-3779656, E-mail: i.bissett@auckland.ac.nz 
ity resulting in impaired GI transit are poorly understood. ${ }^{3}$ The pathophysiology of POI is multifactorial, involving neural, inflammatory, hormonal, and pharmacologic factors that have previously been reviewed in depth. ${ }^{3-6}$ However, little focus has been given to the electrical and mechanical dysfunction linking these factors to the clinical syndrome of POI. Many authors and clinicians have presumed that the entire GI tract is paralysed post-operatively, reflected in the common use of terms such as "paralytic ileus," and "adynamic ileus." These terms reflect the common belief that all POI occurs due to paralysis, though recent work has begun to challenge this view. ${ }^{8-10}$ Additionally, most authors have considered "obligatory POI" and PPOI as part of a continuous spectrum, although others have proposed that these conditions have differing mechanisms and pathophysiology, and may also result from dysfunction in different parts of the gut. ${ }^{11,12}$

Furthermore, the stomach, small intestine, and colon each have distinct roles and functions, with different intrinsic and extrinsic processes controlling motility, and thus may respond and recover differently following surgery. ${ }^{12,13}$ Several studies have suggested that the colon is the final organ in the GI tract to recover normal motility following surgery. ${ }^{14-16}$ However, prior studies investigating post-operative colonic activity have used a heterogeneous range of techniques and methodologies, leading to inconsistent results and conclusions regarding the pathophysiology of POI.

In view of these issues, a critical review of the existing literature is warranted in order to reappraise historical studies, summarize the current body of knowledge, and identify areas requiring further research. The aim of this article was to systematically search and critically review the literature investigating post-operative colonic electrical and mechanical function.

\section{Methods}

\section{Search Strategy}

A systematic search of the literature was performed in July 2017 using the Embase (1947-present) and MEDLINE (1946-present) databases. The following search strategy was used:

1. ileus.mp OR ileus/

2. (postoperativ* OR post operativ* OR surg*).mp.

3. (colon* OR colorect* OR bowel OR (intestin* AND large)).mp.

4. (motor OR peristal* OR pressure OR manometr* OR motility OR contract*).mp.

5. (electrod* OR electric* OR myoelectr* OR slow wave OR spike).mp.

6. 3 ADJ5 (4 OR 5)

7. (1 OR 2) AND 6

A focused search of the scientific literature was also performed using Google Scholar to identify additional relevant articles.

\section{Screening and Synthesis of Evidence}

Titles and abstracts were screened by a single reviewer (C.W.), and a list of full texts for acquisition was developed. Original articles investigating post-operative colonic motor or electrical activity in human patients were included, and evidence from animal models was also used to support human data where relevant. There were no limits regarding the type of operations investigated or methods used, as long as post-operative colonic electrical or mechanical function was reported. Articles solely investigating long-term aberrations in motility following surgery were excluded, as were articles investigating motility following surgery specifically for small or large bowel obstruction. Articles solely reporting clinical recovery of bowel function (ie, time to passage of flatus) were also excluded, as were non-English language articles. Review articles summarising the pathophysiology and management of POI were also scrutinised for further references to primary research. References lists of included articles were manually searched to identify additional studies, including those published prior to indexing of articles in electronic databases.

Studies were summarised in a narrative synthesis, given the heterogeneity of identified evidence. The techniques used to measure post-operative colonic motility were evaluated, as were the specific aberrations in colonic motility reported by these studies. A critical appraisal of studies reporting post-operative colonic motor and electrical function was conducted. No formal grading system was applied to define literature quality, due to the heterogeneity and physiological nature of the included studies.

\section{Results}

\section{Article Identification}

In total, 4552 articles were evaluated and screened (Figure). Nineteen original articles investigating motor or electrical activity were identified and formed the basis of this critical review.

\section{Measurement of Post-operative Colonic Motility}

A range of techniques have been used for the investigation of peri-operative colonic motility, including mucosal or serosal record- 


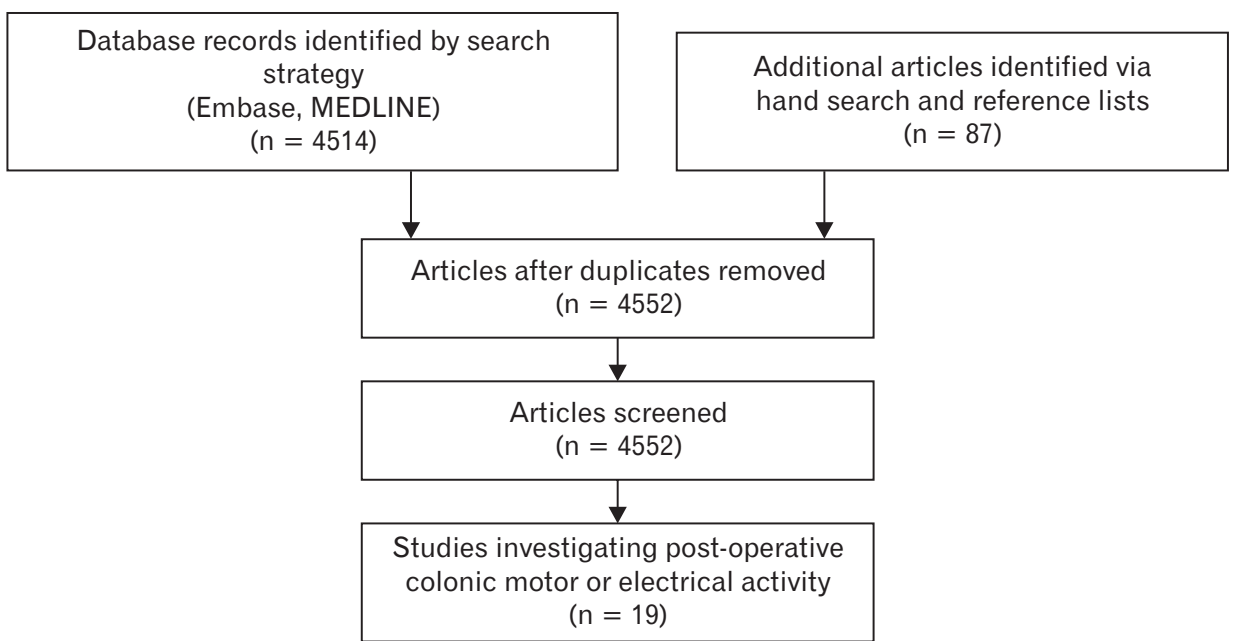

Figure. Flow diagram for the identification and screening of studies. ings of electrical activity, and intraluminal measurements of colonic pressure or tone. Most studies to date have used low-resolution techniques for the measurement of post-operative colonic activity, ${ }^{10,17-19}$ with only one identified recent study using high-resolution (HR) manometry. ${ }^{9}$ Furthermore, most studies have used recording periods of only 2-3 hours on each post-operative day to track colonic recovery following surgery. ${ }^{10,17,20-22}$ Colonic activity is known to vary throughout the day in healthy individuals, and therefore short recording periods may not be representative of the overall recovery of colonic motility following surgery. ${ }^{23,24}$

\section{Post-operative Aberrations in Colonic Motility}

\section{Transit studies}

Classical studies from the 1960's used radiopaque contrast to investigate the recovery of GI transit following laparotomy. ${ }^{15,25,26}$ These showed that contrast introduced into the stomach did not progress past the pylorus for at least 12-24 hours. ${ }^{14,15,25}$ However, contrast introduced directly into the small intestine via a nasoduodenal or nasojejunal tube progressed through the small bowel, taking 6-12 hours to accumulate in the proximal colon. ${ }^{14,15,27}$ The authors also noted that abdominal radiographs taken on the first 2 days post-operatively often showed gas accumulation in the stomach and proximal colon, with little to no small bowel gas. ${ }^{14,15,26}$ Thus, it was inferred that the small bowel remains able to propel ingested air towards the colon. Subsequent studies have shown the presence of small bowel motor and electrical activity as soon as 2 hours following surgery. ${ }^{14,26,28,29}$ However, this finding has never been evaluated in detail using HR techniques, hence it remains unclear whether this represents normal or abnormal motility patterns.
In contrast to the stomach and small bowel, colonic transit is significantly prolonged post-operatively, taking 3-5 days for the return of antegrade propulsive activity in the colon and rectum. ${ }^{14,15}$ Propulsive activity (determined by progression of radio-opaque markers or contrast) appears to recover in a proximal to distal pattern, starting in the right colon, and the sigmoid colon being the final part of the bowel to recover normal transit. ${ }^{16,30}$ In addition, the return of normal colonic transit in POI is strongly correlated with the clinical recovery of bowel function assessed by passage of stool or flatus and tolerance of an oral diet. ${ }^{31}$ No studies investigating regional abnormalities of GI transit in PPOI specifically were identified. More recently, preliminary data using the SmartPill to measure post-operative GI transit demonstrated significantly delayed gastric and colonic transit following sigmoid colectomy compared with healthy control data, and a relatively preserved small intestinal transit time of approximately 6 hours, ${ }^{32}$ in keeping with these historical studies.

Finally, several studies have identified that cecal and right colonic transit is significantly impaired for up to 14 days following formation of a temporary loop ileostomy, presumably due to the proximal disruption in enteric continuity and diversion of intestinal contents. $^{33,34}$

\section{Electromechanical studies}

Nineteen identified studies investigated post-operative colonic motility following a range of colonic and non-colonic procedures. All but one study used low-resolution techniques for electrical or pressure recordings, and most studies used intermittent recordings of colonic motility throughout the post-operative period. The methods of analysis showed substantial heterogeneity between studies; 
some reported activity as a motility index, others number of events per unit time, and others as time until occurrence of particular motor or electrical patterns. All identified studies investigated recovery of "obligatory POI" following surgery; no studies were identified investigating the changes in colonic motility or transit occurring specifically in PPOI.

A summary and appraisal of the 19 identified studies investigating post-operative colonic motor and electrical activity is provided in Table 1 and Table 2 respectively. In contrast to the traditional view of post-operative GI paralysis, numerous studies have shown that colonic electrical and motor activity can be detected as early as the first post-operative day following major abdominal surgery. However, given the impairment in colonic transit, this activity is unlikely to represent events associated with mass movements of stool such as high-amplitude propagating sequences (HAPS).

The terms "electrical control activity (ECA)" and "electrical response activity (ERA)" have previously been used to describe perioperative colonic electrical activity, though are now viewed as historic, with modern authors generally preferring the terms "slow wave" and "spike" activity respectively. However, these terms are included here for consistency as part of a synthesis of historical literature. A full discussion of these historical terms is provided elsewhere. ${ }^{35,36}$

Multiple studies demonstrated the presence of colonic slow waves (historically termed ECA) on the first post-operative day. ${ }^{20,37,38}$ This was present at a range of frequencies, usually reported as 2-9 cpm, 9-14 cpm, and occasionally a high range of 20-28 cpm. ${ }^{20,28,37,39}$ The dominant frequency identified varied by anatomical location; 2 studies reported $3 \mathrm{cpm}$ activity in the sigmoid colon, ${ }^{40,41}$ whereas other studies found that 9-14 cpm slow wave frequencies predominate in the right, transverse, and left colon during the first few days post-operatively. ${ }^{20,28,37,38}$ Analyses of slow wave frequencies over time showed conflicting results. Condon et $\mathrm{al}^{20,38}$ showed a downshift from mid- to low-range slow wave frequencies occurs first in the right colon (day 2-3), and then the left colon (day 6-7). Conversely, Waldhausen et $\mathrm{al}^{28}$ reported an increase of high frequency $(20-28 \mathrm{cpm})$ activity in the transverse colon until postoperative day 5 .

Spike bursts or ERA representing the occurrence of smooth muscle contractions, was reported more variably. Historical studies have generally classified spike activity as either "discrete ERA (DERA)," defined as spikes occurring in clusters on top of slow waves, or "continuous ERA (CERA)," defined as continuous spike activity occurring across consecutive slow waves. Multiple studies demonstrated the presence of DERA as early as the first postoperative day, suggesting "myogenic" contractions due to slow wave activity return relatively early. ${ }^{20,28,37,42,43} \mathrm{CERA}$, thought to represent neurogenic activity, was usually first detected on day 3-5, associated with long-duration spike bursts, and the appearance of spike activity propagating in antegrade directions in the right and left colon, ${ }^{38}$ possibly correlating with HAPS. Similar to other analyses, spike activity generally returned in a proximal to distal manner in the colon. Some studies also reported very high frequency spike activity occurring at $>25 \mathrm{cpm},{ }^{44}$ though the significance of this activity remains unclear, especially as motor activity occurring at this frequency has not been described.

Studies investigating pressure activity have also reported inconsistent results. All studies were limited to the distal colon and rectum; no studies used manometry to assess ascending or transverse colonic activity post-operatively. Some studies reported the colon was completely quiescent for 3-10 days post-operatively, ${ }^{45}$ while others identified uncoordinated phasic activity occurring within the first day. ${ }^{18,19,22,46}$

Conversely, the only study using HR manometry to investigate post-operative colonic motility showed a hyperactive distal colonic response to surgery, characterised by cyclic motor patterns (CMP) occurring at 2-4 cpm, present for up to $90 \%$ of the post-operative recordings, and an absence of HAPS. ${ }^{9}$ This was observed in 7 patients undergoing laparoscopic right hemicolectomy, and one undergoing an open trial dissection and loop ileostomy, suggesting it may occur as a generic response to surgery. However, recordings in this study were only obtained for 16 hours post-operatively, preventing correlation of this activity with the resolution of POI. Several low-resolution manometry studies also demonstrated increased $3 \mathrm{cpm}$ motor activity in the sigmoid colon following non-colonic abdominal operations, ${ }^{19,40}$ possibly correlating with the hyperactive CMP activity observed by Vather et al. ${ }^{9}$ Huge et $\mathrm{al}^{10}$ reported an increased distal colonic tone following left colonic or rectal surgery, though the significance of this in the clinical context of POI is unknown.

Some differences within and between studies may be explained by the types of operations investigated. Several studies pooled results from a range of procedures, thus making it difficult to determine the precise effects of surgical variables on post-operative colonic motility. ${ }^{20,28,37,38,42,47}$ Wilson et al ${ }^{21}$ suggested normal colonic motility recovers more slowly following abdominal surgery, compared with non-abdominal procedures, though no differences in recovery were observed between different intra-abdominal operations (cholecystectomy vs gastrectomy vs colectomy). Other low-resolution studies have suggested that colonic motility is significantly reduced following rectal or left-sided colonic resections, compared with that 


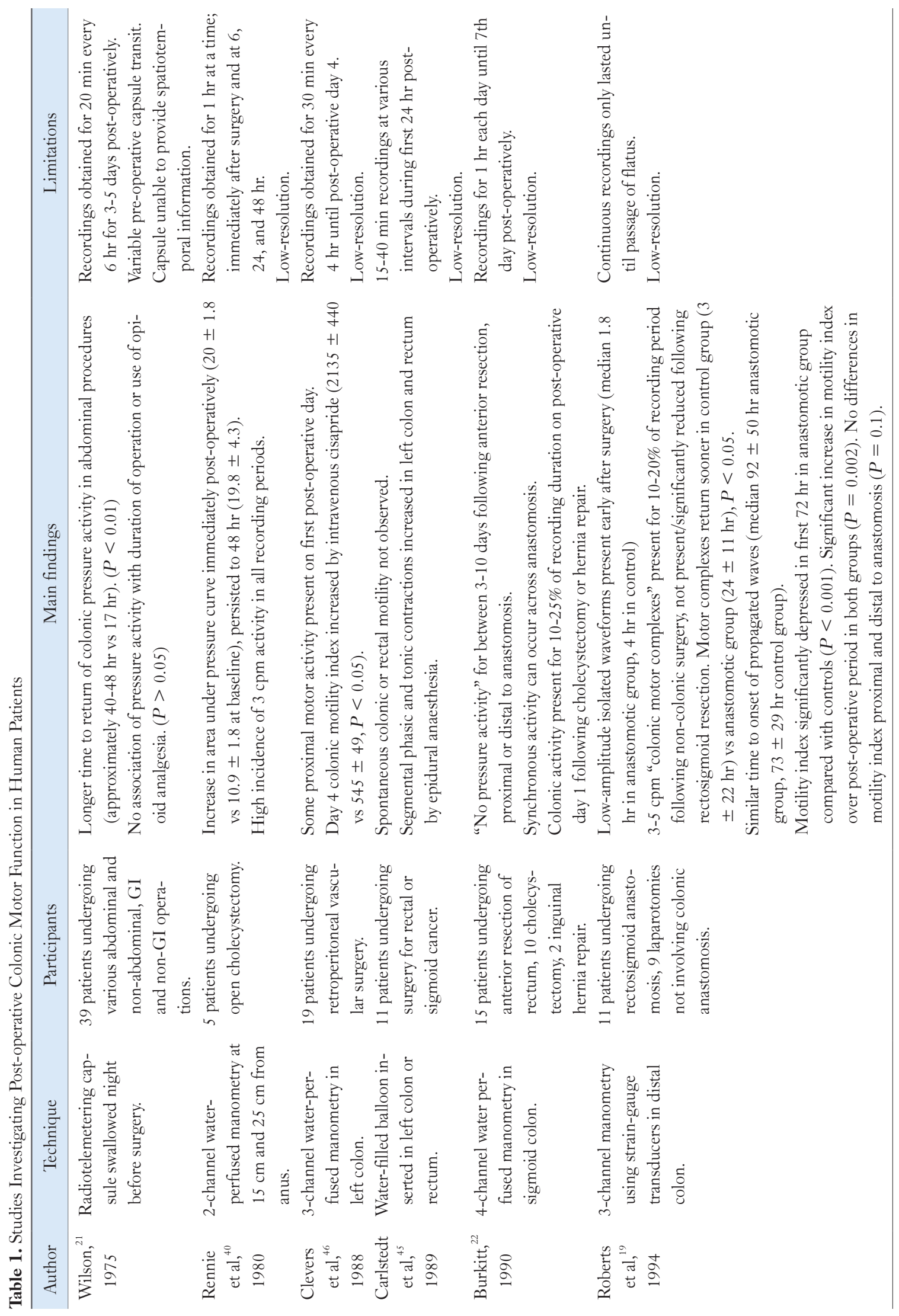




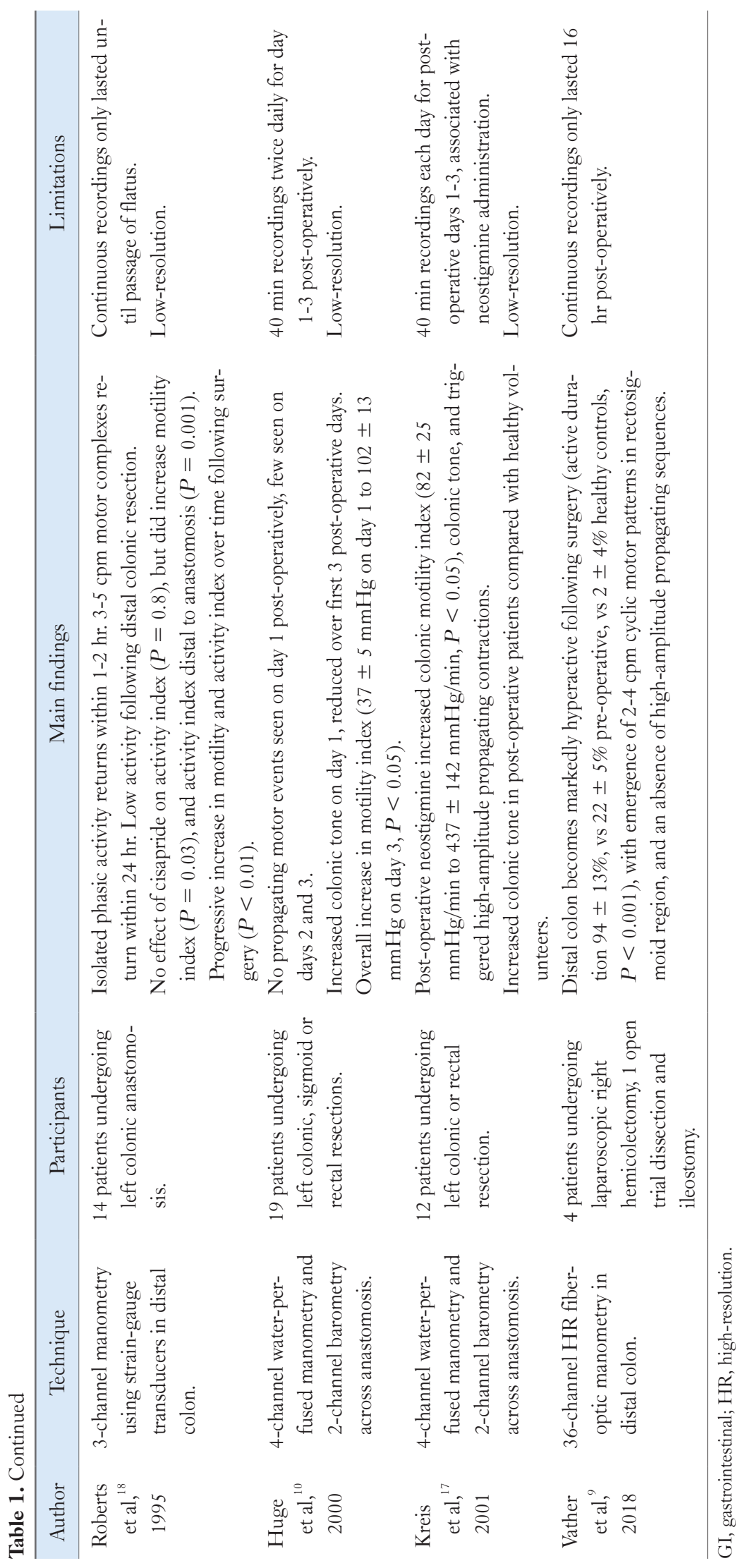




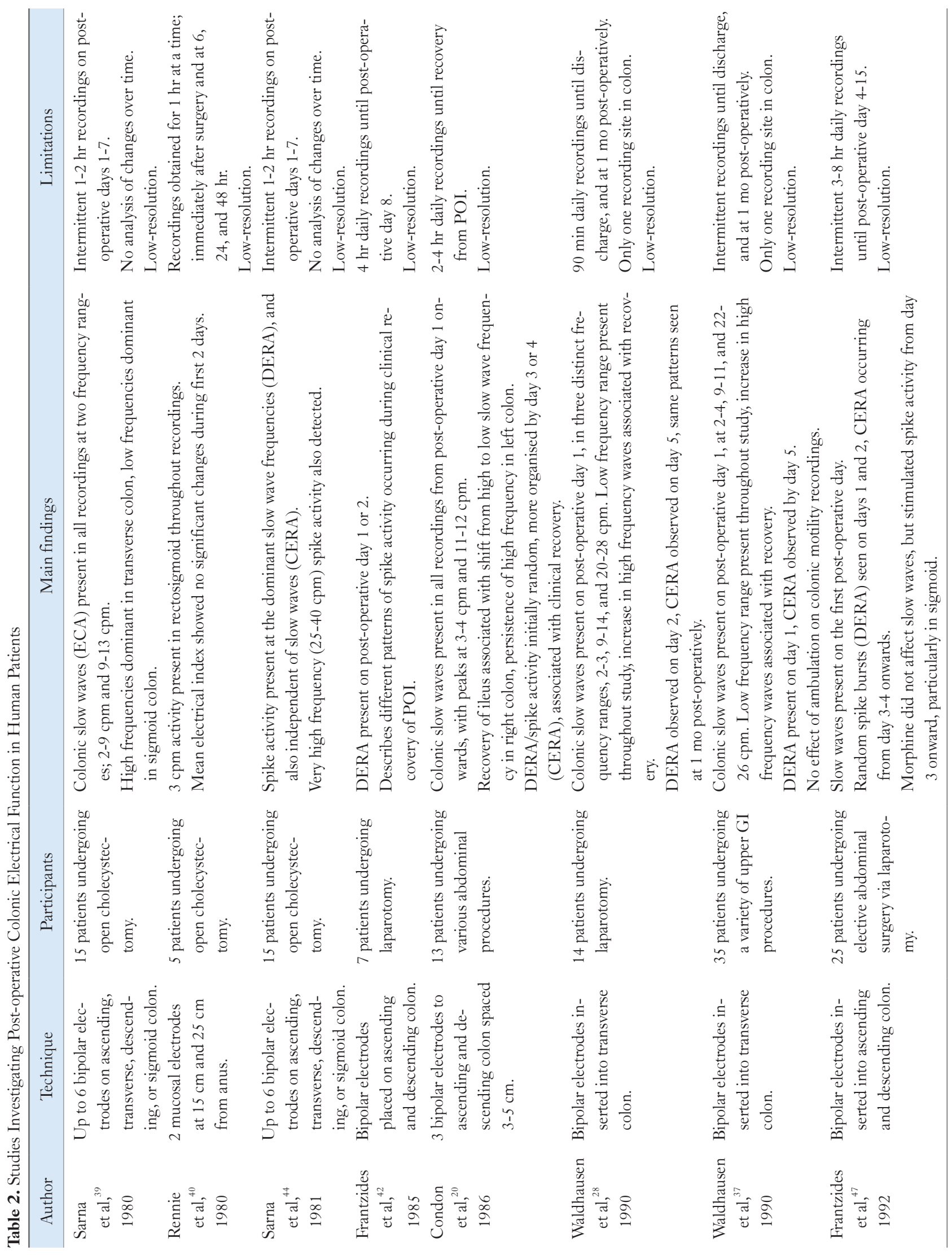




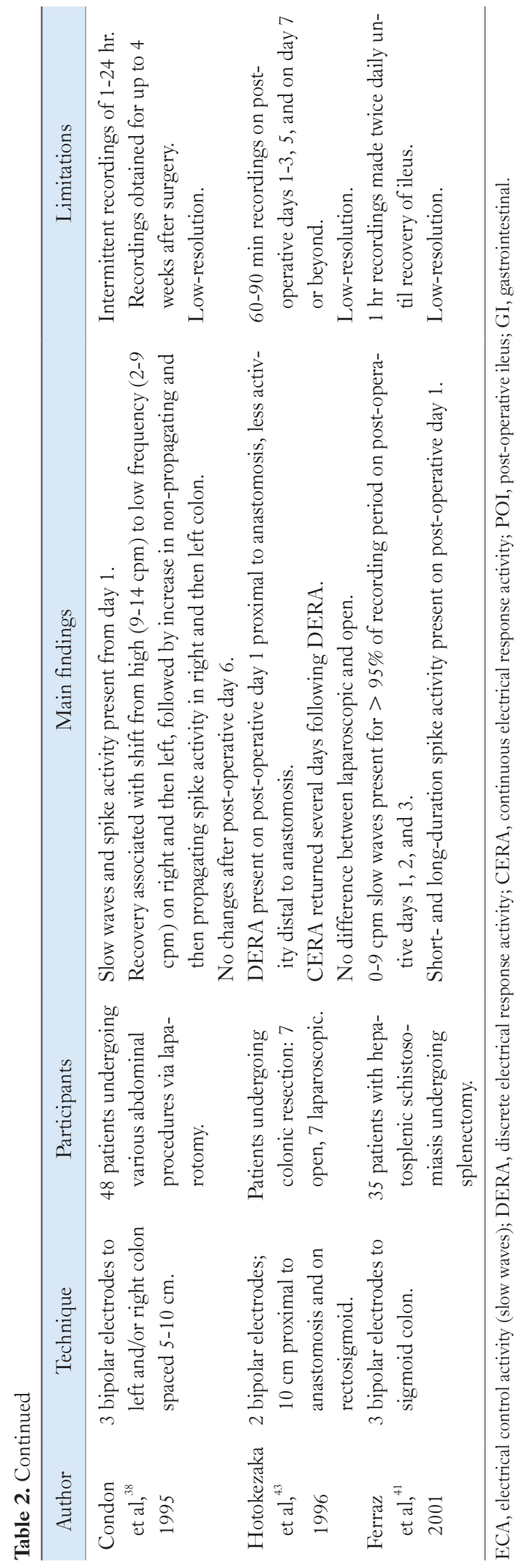

observed following non-colonic surgery. ${ }^{19,22}$ However, the low-resolution nature of these studies has prevented precise evaluation of the electrical and motor patterns occurring post-operatively following different surgical procedures.

Furthermore, there may be significant differences in postoperative motility between left- and right-sided colonic resections. Distal colonic motor activity appears to be significantly depressed following rectal or left-sided colonic resections, ${ }^{10,17-19,22,45}$ in contrast to the hyperactive distal colonic response observed following right hemicolectomy and non-colonic surgery. ${ }^{9,40}$ This may represent technical limitations inherent in low-resolution recordings, but may also be due to resection of a "rectosigmoid pacemaker" region responsible for the increased distal colonic cyclic activity observed following right hemicolectomy. ${ }^{9,48,49}$ This hyperactive cyclic pattern has been hypothesised to act as a functional brake, ${ }^{48,50}$ limiting rectal filling and potentially explaining the slower recovery of bowel function following right-sided compared with left-sided colonic resections. $^{48,49,51,52}$

Overall, studies showed that post-operative colonic dysfunction returns to "normal" between 3 and 6 days following laparotomy, with the proximal colon appearing to recover earlier than the distal colon. ${ }^{20,37,38}$ These findings are in keeping with the transit studies described above, and with evidence from animal studies conducted using similar techniques. ${ }^{29,53}$ However, the precise changes in motility characterising recovery from POI remain incompletely defined. Some studies have shown relatively little change in motility index over the post-operative period, ${ }^{19,22}$ while others have suggested recovery is characterised by a progressive increase in distal colonic motility index. ${ }^{10,17}$ Electrical studies have suggested that recovery occurs in a proximal-to-distal direction, and is characterised by a "downshift" of slow waves from high to low frequency, ${ }^{20,38}$ and a progressive recovery of spike activity, ${ }^{42}$ with the occurrence of propagating, likely-neurogenic activity such as CERA closely correlating with clinical recovery of POI on post-operative day ${ }^{3-6,20,28,38,43}$ Longterm studies using serosal electrodes showed no difference between motility patterns obtained on post-operative day 5 or 6 and 1 month post-operatively. $28,37,38$

\section{Pharmacological studies}

Most studies did not report the agents used for induction and maintenance of anaesthesia during surgery, and therefore no conclusions were able to be drawn regarding the effects of anaesthetic agents on post-operative colonic motility. However, animal studies have shown that while these agents depress colonic motility, their short half-life generally limits their implication in the pathogenesis 
of POI. $^{54,55}$

Several studies have investigated the effects of pharmacological treatments on post-operative colonic motility, but these have largely been limited by the use of low-resolution techniques. Studies investigating opioids have reported variable results, with some studies showing morphine to invoke an increase in the frequency and amplitude of rhythmic contractions, and others showing a suppression of contractile activity. ${ }^{20,44,47,56-58}$ A number of factors may contribute to these differences, including the use of techniques with limited spatiotemporal resolution, as well as variations in use of the term "motility" and whether this refers to HAPS and/or other low-amplitude phasic/segmental activity such as CMP. It has been hypothesised that opioids may cause reduced excitability of inhibitory enteric neurons, resulting in disinhibition of intrinsic myogenic activity and an increase in segmental motor activity, exacerbating the effects of surgery on colonic activity. ${ }^{59,60}$ However, the effects of opiates on GI motor activity have not been assessed using HR techniques, and their effects on the colon and other parts of the gut following surgery remain unclear.

Other low-resolution studies have demonstrated that neostigmine, cisapride, and epidural anaesthesia increase the distal colonic motility index post-operatively, though the precise types of motor patterns stimulated by these interventions and their implications for transit remain unknown. ${ }^{18,19,45,46}$

\section{Discussion}

It has been evident since the 1960's that the stomach, small intestine, and colon respond and recover differently following surgery, likely due to their dissimilar mechanisms controlling motility. ${ }^{13}$ This systematic critical review of the literature identified a range of studies investigating post-operative colonic motility, which have used heterogeneous methods, and reported variable results, with some studies showing an absence of pressure activity post-operatively, ${ }^{45}$ and others demonstrating a hyperactive response in the distal colon. ${ }^{9}$

The results of this review demonstrate that reliable data on aberrant motility patterns contributing to POI in each part of the gut remains limited, though the colon appears to be the final organ to recover normal motility at day 3-5 post-operatively. ${ }^{14,15,20,38}$ Therefore, the duration of colonic dysmotility may be the rate-limiting factor in the clinical resolution of "obligatory POI" in most cases after major abdominal surgery. ${ }^{20,38,53}$ Importantly, no identified studies specifically investigated GI motility in patients with prolonged ileus, and the relative importance of the different regions of the gut in PPOI therefore remains unknown. However, the presence of small bowel gas and distension in patients with PPOI, as is also commonly identified in abdominal X-rays, likely implies a different pattern of GI dysfunction. ${ }^{14,15,26}$ Furthermore, it is interesting to note that most authors consider an ileus to become prolonged on the third to fifth post-operative day, corresponding to the reported time for recovery of normal colonic motility following surgery. ${ }^{1,5}$ Presumably, failure of any part of the GI tract to recover within this time period may result in the occurrence of PPOI, or an exaggerated inflammatory state might intervene to promote $\mathrm{PPOI}{ }^{3}$

While transit is impaired post-operatively due to abnormal motility, the GI tract is clearly not routinely quiescent following major abdominal surgery. Colonic slow waves and spike activity have been detected on the first post-operative day, ${ }^{20,28,37,38,42,43}$ while a recent HR manometry study showed the distal colon becomes markedly hyperactive immediately following surgery. ${ }^{9}$ Some authors have even suggested the concept of post-operative GI paralysis should be abandoned; ${ }^{26}$ this is clearly the case for "obligatory POI," but it is unknown whether this also applies to patients with PPOI. Acute colonic pseudo-obstruction (also referred to as Ogilvie's syndrome) is a similar, more severe syndrome of colonic dysmotility which may occur post-operatively, though the precise abnormalities in motility underlying this phenomenon also remain unknown. ${ }^{61}$

The studies identified in this review had heterogeneous methodologies, which has likely contributed to the marked variability in reported results. The common use of low-resolution techniques has limited the spatiotemporal detail of obtained electromechanical data, and the results of these studies should be interpreted with caution because specific motility patterns may be missed or mis-interpreted. ${ }^{62,63}$ The metrics used to measure motility also varied greatly; use of a "motility index" alone is likely insufficient due to the limited detail it provides about the classes, organization and directions of activity patterns occurring. Dinning et $\mathrm{al}^{62}$ recently demonstrated the importance of HR techniques in the measurement of colonic motor activity. At $10 \mathrm{~cm}$ spacing, less than $5 \%$ of the propagating activity observed at $1 \mathrm{~cm}$ spacing can been seen, and more than half of all propagating events identified are labelled incorrectly. ${ }^{62}$ Therefore, the results of low-resolution studies should be interpreted with caution, given the high likelihood they do not accurately represent the totality of colonic motor patterns actually occurring. The type, frequency, amplitude, direction, and extent of propagating motor and electrical events are important features of GI motility; therefore future studies should ideally use HR techniques in order to accurately determine these characteristics in POI and PPOI.

While it is clear that different regions of the GI tract respond in distinct manners post-operatively, this may also be the case for 
different parts of the colon. A variety of specific slow wave frequencies have been detected in different regions of the colon, and the changes in electromechanical activity characterising recovery appear to occur in a proximal to distal manner. ${ }^{20,38}$ Manometry recordings have been limited to the sigmoid and descending colon, and it remains unknown how the motor activity of the ascending and transverse colon is affected post-operatively. It has recently been shown that the distal colon becomes hyperactive following surgery, though how this relates to the clinical resolution of POI remains unclear, and this should be assessed by future HR manometry studies.

There are few feasible strategies for HR electrical mapping of colonic electrical activity post-operatively, hence most studies to date have used bipolar needle electrodes. Prolonged HR recordings may be possible in chronically instrumented animals, ${ }^{64}$ but this technique cannot be readily applied to humans using currently-available techniques. Electrogastrography has been applied in humans in HR to record gastric electrical activity from the body surface, but it is unknown if these techniques are sufficiently reliable, and whether similar techniques can be applied to non-invasively measure colonic motility. ${ }^{65-68}$ Serosal HR electrode arrays have previously been used for short-duration intra-operative mapping of both the stomach and small intestine. ${ }^{69}$ This technique has not yet been applied to the colon, but could aid in clarifying the relationship between electrical activity and motor patterns if applied in conjunction with HR manometry.

An improved understanding of the abnormalities in motility underlying POI and PPOI would be valuable for the development of novel pharmacological therapies or other interventions such as GI pacing or nerve stimulation..$^{70-72}$ Many of the current rodent models of ileus are based on measurements of "obligatory POI" in the small intestine following laparotomy and mechanical manipulation of the small intestine. ${ }^{73-75}$ It remains unclear how accurately this simulates the insult associated with major colorectal surgery in human patients. ${ }^{6}$ Experimental animal studies are clearly valuable for investigation of POI and PPOI, though authors should be wary of how accurately these experimental models extrapolate to human patients undergoing abdominal surgery.

Few studies to date have considered the pathophysiology of obligatory POI and PPOI separately, and these have largely been assumed to represent a continuum of the clinical syndrome of ileus. ${ }^{3,11}$ However, there is little evidence to support this claim, and it is entirely possible that POI and PPOI result from different mechanisms and different changes in GI motility. ${ }^{11,12}$ No studies have characterised the abnormalities in GI motility occurring during PPOI in humans, and this remains an area requiring further research. It is important to note that the studies identified in the present review represent a profile of "obligatory POI" following laparotomy, and should not be extrapolated to patients with PPOI. Furthermore, the precise electromechanical aberrations in colonic motility occurring following different surgical procedures (ie, left vs right colonic resection, colonic vs non-colonic surgery, and abdominal vs non-abdominal surgery) remain poorly defined and require further investigation.

There are several limitations of the present review, including the inability to synthesise evidence quantitatively due to the heterogeneity of literature, techniques and outcomes identified. Colonic motility was the focus of the present article, given its putative role in the duration of "obligatory POI." However, post-operative aberrations in gastric and small intestinal motility were not evaluated, and may also be important to an overall understanding of POI and PPOI. ${ }^{76}$ Finally, most included studies were historical, and only one study included patients undergoing laparoscopic procedures within a modern ERAS programme. ${ }^{9}$ Thus the generalisability of the results from historical studies to current practice is uncertain.

In summary, colonic motility appears to be important in the genesis and resolution of POI. Colonic electromechanical activity does not cease post-operatively, and the distal colon becomes hyperactive immediately following surgery. "Normal" motility appears to recover in a proximal to distal direction, and temporally correlates with clinical recovery of bowel function. Future studies should use HR techniques in clearly defined cohorts of patients to accurately characterise the changes in colonic motility occurring in POI and PPOI, and determine how these correlate with clinical resolution of ileus.

Financial support: This study was provided by the Royal Australasian College of Surgeons (James Ramsay Project Grant) and the New Zealand Health Research Council.

\section{Conflicts of interest: None.}

Author contributions: Cameron I Wells, Gregory O'Grady, and Ian P Bissett contributed to conception and design of the study, interpretation of data, and drafting and revising of the manuscript; Cameron I Wells acquired and analysed data; and all authors have given final approval of the version of the article to be published.

\section{References}

1. Vather R, Trivedi S, Bissett I. Defining postoperative ileus: results of a 
systematic review and global survey. J Gastrointest Surg 2013;17:962972.

2. Peters EG, Dekkers M, van Leeuwen-Hilbers FW, et al. Relation between postoperative ileus and anastomotic leakage after colorectal resection: a post hoc analysis of a prospective randomized controlled trial. Colorectal Dis 2017;19:667-674.

3. Vather R, O'Grady G, Bissett IP, Dinning PG. Postoperative ileus: mechanisms and future directions for research. Clin Exp Pharmacol Physiol 2014;41:358-370.

4. Bragg D, El-Sharkawy AM, Psaltis E, Maxwell-Armstrong CA, Lobo DN. Postoperative ileus: recent developments in pathophysiology and management. Clin Nutr 2015;34:367-376.

5. Venara A, Neunlist M, Slim K, et al. Postoperative ileus: pathophysiology, incidence, and prevention. J Visc Surg 2016;153:439-446.

6. Stakenborg N, Gomez-Pinilla PJ, Boeckxstaens G. Postoperative ileus: pathophysiology, current therapeutic approaches. Gastrointestinal Pharmacology 2017;239:39-57.

7. Neely J, Catchpole B. Ileus: the restoration of alimentary-tract motility by pharmacological means. Br J Surg 1971;58:21-28.

8. Patak MA, Froehlich JM, von Weymarn C, Breitenstein S, Zollikofer CL, Wentz KU. Non-invasive measurement of small-bowel motility by MRI after abdominal surgery. Gut 2007;56:1023-1025.

9. Vather R, O'Grady G, Lin AY, et al. Hyperactive cyclic motor activity in the distal colon after colonic surgery as defined by high-resolution colonic manometry. Br J Surg 2018;105:907-917.

10. Huge A, Kreis ME, Zittel TT, Becker HD, Starlinger MJ, Jehle EC. Postoperative colonic motility and tone in patients after colorectal surgery. Dis Colon Rectum 2000;43:932-939.

11. Luckey A, Livingston E, Taché Y. Mechanisms and treatment of postoperative ileus. Arch Surg 2003;138:206-214.

12. Morris IR. Does postoperative ileus exist? J Crit Care 2009;24:614-616.

13. Ruwart MJ, Klepper MS, Rush BD. Carbachol stimulation of gastrointestinal transit in the postoperative lleus rat. J Surg Res 1979;26:18-26.

14. Nachlas MM, Younis MT, Roda CP, Wityk JJ. Gastrointestinal motility studies as a guide to postoperative management. Ann Surg 1972;175:510-522.

15. Rothnie NG, Harper RK, Catchpole BN. Early postoperative gastrointestinal activity. Lancet 1963;282:64-67.

16. Tollesson PO, Cassuto J, Rimbäck G. Patterns of propulsive motility in the human colon after abdominal operations. Eur J Surg 1992;158:233236.

17. Kreis ME, Kasparek M, Zittel TT, Becker HD, Jehle EC. Neostigmine increases postoperative colonic motility in patients undergoing colorectal surgery. Surgery 2001;130:449-456.

18. Roberts JP, Benson MJ, Rogers J, Deeks JJ, Wingate DL, Williams NS. Effect of cisapride on distal colonic motility in the early postoperative period following left colonic anastomosis. Dis Colon Rectum 1995;38:139145 .

19. Roberts JP, Benson MJ, Rogers J, Deeks JJ, Williams NS. Characterization of distal colonic motility in early postoperative period and effect of colonic anastomosis. Dig Dis Sci 1994;39:1961-1967.

20. Condon RE, Frantzides CT, Cowles VE, Mahoney JL, Schulte WJ,
Sarna SK. Resolution of postoperative ileus in humans. Ann Surg 1986;203:574-581.

21. Wilson J. Postoperative motility of the large intestine in man. Gut 1975;16:689-692.

22. Burkitt D, Donovan I. Intraluminal pressure adjacent to left colonic anastomoses. Br J Surg 1990;77:1288-1290.

23. Bowling TE. Does disorder of gastrointestinal motility affect food intake in the post-surgical patient? Proc Nutr Soc 1994;53:151-157.

24. Scott SM. Manometric techniques for the evaluation of colonic motor activity: current status. Neurogastroenterol Motil 2003;15:483-513.

25. Wells C, Rawlinson K, Tinckler L, Jones H, Saunders J. Ileus and postoperative intestinal motility. Lancet 1961;2:136-137.

26. Wells C, Rawlinson K, Tinckler L, Jones H, Saunders J. Postoperative gastrointestinal motility. Lancet 1964;283:4-10.

27. Noer T. Roentgenological transit time through the small intestine in the immediate postoperative period. Acta Chir Scand 1968;134:577-580.

28. Waldhausen JH, Shaffrey ME, Skenderis BS 2nd, Jones RS, Schirmer BD. Gastrointestinal myoelectric and clinical patterns of recovery after laparotomy. Ann Surg 1990;211:777-784; discusstion 785.

29. Graber JN, Schulte WJ, Condon RE, Cowles VE. Relationship of duration of postoperative ileus to extent and site of operative dissection. Surgery 1982;92:87-92.

30. Tollesson P, Cassuto J, Faxen A, Björk L. A radiologic method for the study of postoperative colonic motility in humans. Scand J Gastroenterol 1991;26:887-896.

31. van Bree SH, Bemelman WA, Hollmann MW, et al. Identification of clinical outcome measures for recovery of gastrointestinal motility in postoperative ileus. Ann Surg 2014;259:708-714.

32. Vilz TO, Pantelis D, Lingohr P, et al. SmartPill ${ }$ as an objective parameter for determination of severity and duration of postoperative ileus: study protocol of a prospective, two-arm, open-label trial (the PIDuSA study). BMJ Open 2016;6:e011014.

33. Ali JM, Rajaratnam SG, Upponi S, Hall NR, Fearnhead NS. Colonic transit in the empty colon after defunctioning ileostomy: do we really know what happens? Tech Coloproctol 2015;19:165-172.

34. Huang S, Theophilus M, Cui J, et al. Colonic transit: what is the impact of a diverting loop ileostomy? ANZ J Surg 2017;87:795-799.

35. Sarna SK. Physiology and pathophysiology of colonic motor activity (1). Dig Dis Sci 1991;36:827-862.

36. Sarna SK. Physiology and pathophysiology of colonic motor activity (2). Dig Dis Sci 1991;36:998-1018.

37. Waldhausen JH, Schirmer BD. The effect of ambulation on recovery from postoperative ileus. Ann Surg 1990;212:671-677.

38. Condon RE, Cowles VE, Ferraz AA, et al. Human colonic smooth muscle electrical activity during and after recovery from postoperative ileus. Am J Physiol 1995;269(3 Pt 1):G408-G417.

39. Sarna SK, Bardakjian BL, Waterfall WE, Lind JF. Human colonic electrical control activity (ECA). Gastroenterology 1980;78:1526-1536.

40. Rennie JA, Christofides ND, Mitchenere P, et al. Neural and humoral factors in postoperative ileus. Br J Surg 1980;67:694-698.

41. Ferraz AA, Wanderley GJ, Santos MA Jr, Mathias CA, Araújo JG Jr, Ferraz EM. Effects of propranolol on human postoperative ileus. Dig 
Surg 2001;18:305-310.

42. Frantzides CT, Condon RE, Cowles V. Early postoperative colon electrical response activity. Surg Forum 1985;36:163-165.

43. Hotokezaka M, Dix J, Mentis EP, Minasi JS, Schirmer BD. Gastrointestinal recovery following laparoscopic vs open colon surgery. Surg Endosc 1996;10:485-489.

44. Sarna SK, Waterfall WE, Bardakjian BL, Lind JF. Types of human colonic electrical activities recorded postoperatively. Gastroenterology 1981;81:61-70.

45. Carlstedt A, Nordgren S, Fasth S, Appelgren L, Hultén L. Epidural anaesthesia and postoperative colorectal motility - a possible hazard to a colorectal anastomosis. Int J Colorectal Dis 1989;4:144-149.

46. Clevers GJ, Smout AJPM, Akkermans LMA, Wittebol P. Restoration of gastrointestinal transit and colonic motility after major abdominal surgery; effects of cisapride. Surg Res Comm 1988;4:205-213.

47. Frantzides CT, Cowles V, Salaymeh B, Tekin E, Condon RE. Morphine effects on human colonic myoelectric activity in the postoperative period. Am J Surg 1992;163:144-148; discusstion 148-149.

48. Lin AY, Dinning PG, Milne T, Bissett IP, O'Grady G. The 'rectosigmoid brake': review of an emerging neuromodulation target for colorectal functional disorders. Clin Exp Pharmacol Physiol 2017;44:719-728.

49. Yuan L, O'Grady G, Milne T, Jaung R, Vather R, Bissett IP. Prospective comparison of return of bowel function after left versus right colectomy. ANZ J Surg 2018;88:E242-E247.

50. Lin AY, Du P, Dinning PG, et al. High-resolution anatomic correlation of cyclic motor patterns in the human colon: Evidence of a rectosigmoid brake. Am J Physiol Gastrointest Liver Physiol 2017;312:G508-G515.

51. Kummer A, Slieker J, Grass F, Hahnloser D, Demartines N, Hübner M. Enhanced recovery pathway for right and left colectomy: comparison of functional recovery. World J Surg 2016;40:2519-2527.

52. Moghadamyeghaneh Z, Hwang GS, Hanna MH, et al. Risk factors for prolonged ileus following colon surgery. Surg Endosc 2016;30:603-609.

53. Woods JH, Erickson LW, Condon RE, Schulte WJ, Sillin LF. Postoperative ileus: a colonic problem? Surgery 1978;84:527-533.

54. Condon RE, Cowles V, Ekbom GA, Schulte WJ, Hess G. Effects of halothane, enflurane, and nitrous oxide on colon motility. Surgery 1987;101:81-85.

55. Giuffre M, Gross JB. The effects of nitrous oxide on postoperative bowel motility. Anesthesiology 1986;65:699-700.

56. Neely J. The effects of analgesic drugs on gastro-intestinal motility in man. Br J Surg 1969;56:925-929.

57. Ferraz AA, Cowles VE, Condon RE, Schulte WJ. Opioid and nonopioid analgesic drug effects on colon contractions in monkeys. Dig Dis Sci 1995;40:1417-1419.

58. Ekbom G, Schulte WJ, Condon RE, Woods JH, Cowles V. Effects of narcotic analgesics on bowel motility in subhuman primates. J Surg Res 1980;28:293-296.

59. Wood JD. Opioids, the enteric nervous system, and postoperative ileus.
Semin Colon Rectal Surg 2005;16:188-196.

60. Wood JD, Galligan JJ. Function of opioids in the enteric nervous system. Neurogastroenterol Motil 2004;16(suppl 2):17-28.

61. Wells CI, O'Grady G, Bissett IP. Acute colonic pseudo-obstruction: a systematic review of aetiology and mechanisms. World J Gastroenterol 2017;23:5634-5644.

62. Dinning PG, Wiklendt L, Gibbins I, et al. Low-resolution colonic manometry leads to a gross misinterpretation of the frequency and polarity of propagating sequences: Initial results from fiber-optic high-resolution manometry studies. Neurogastroenterol Motil 2013;25:e640-e649.

63. O'Grady G, Du P, Cheng LK, et al. Origin and propagation of human gastric slow-wave activity defined by high-resolution mapping. Am J Physiol Gastrointest Liver Physiol 2010;299:G585-G592.

64. Ver Donck L, Lammers WJ, Moreaux B, et al. Mapping slow waves and spikes in chronically instrumented conscious dogs: implantation techniques and recordings. Med Biol Eng Comput 2006;44:170-178.

65. O'Grady G, Abell TL. Gastric arrhythmias in gastroparesis: low and high resolution mapping of gastric electrical activity. Gastroenterol Clin North Am 2015;44:169-184.

66. Gharibans AA, Kim S, Kunkel D, Coleman TP. High-resolution electrogastrogram: a novel, noninvasive method for determining gastric slowwave direction and speed. IEEE Trans Biomed Eng 2017;64:807-815.

67. Calder S, O'Grady G, Cheng LK, Peng Du. A theoretical analysis of electrogastrography (EGG) signatures associated with gastric dysrhythmias. IEEE Trans Biomed Eng 2017;64:1592-1601.

68. Berbari EJ. High-resolution electrocardiography. Crit Rev Biomed Eng 1988;16:67-103.

69. Angeli TR, O'Grady G, Vather R, Bissett IP, Cheng LK. Intra-operative high-resolution mapping of slow wave propagation in the human jejunum: feasibility and initial results. Neurogastroenterol Motil Published Online First: 1 Mar 2018. doi: 10.1111/nmo.13310.

70. Berger T, Kewenter J, Kock NG. Response to gastrointestinal pacing: antral, duodenal and jejunal motility in control and postoperative patients. Ann Surg 1966;164:139-144.

71. Bilgutay AM, Wingrove R, Griffen WO, Bonnabeau RC Jr, Lillehei CW. Gastro-intestinal pacing: a new concept in the treatment of ileus. Ann Surg 1963;158:338-348.

72. Stakenborg N, Wolthuis AM, Gomez-Pinilla PJ, et al. Abdominal vagus nerve stimulation as a new therapeutic approach to prevent postoperative ileus. Neurogastroenterol Motil 2017;29:e13075.

73. Boeckxstaens GE, de Jonge WJ. Neuroimmune mechanisms in postoperative ileus. Gut 2009;58:1300-1311.

74. Bauer AJ, Boeckxstaens GE. Mechanisms of postoperative ileus. Neurogastroenterol Motil 2004;16:54-60.

75. Wouters MM, Boeckxstaens GE. Neuroimmune mechanisms in functional bowel disorders. Neth J Med 2011;69:55-61.

76. Smith J, Kelly KA, Weinshilboum RM. Pathophysiology of postoperative ileus. Arch Surg 1977;112:203-209. 